\section{Sequence Verification as Quality-Control Step for Production of cDNA Microarrays}

BioTechniques 31:62-65 (July 2001)

\begin{abstract}
To generate CDNA arrays in our core laboratory, we amplified about 2300 PCR products from a human, sequence-verified cDNA clone library. As a quality-control step, we sequenced the PCR products immediately before printing. The sequence information was used to search the GenBank ${ }^{\circledR}$ database to confirm the identities. Although these clones were previously sequence verified by the company, we found that only $79 \%$ of the clones matched the original database after handling. Our experience strongly indicates the necessity to sequence verify the clones at the final stage before printing on microarray slides and to modify the gene list accordingly.
\end{abstract}

\section{INTRODUCTION}

Microarrays are powerful tools that can help answer many different biological questions, including the classification of diseases and identification of differentially expressed genes (3-5). Microarrays are comprised of hundreds or thousands of individual genes printed on a single, glass microscope slide (9). The identity of each cDNA clone printed on the chip is provided in a gene list to provide a road map for accurate data analysis and for further investigations with genes of interest that have been highlighted on the microarrays. The cDNA clone library used for building the microarray slides in our core laboratory was purchased from Research Genetics (Huntsville, AL, USA) and originated from the I.M.A.G.E. Consortium (6). To produce a microarray, thousands of cDNAs are first obtained by PCR amplification from a source of DNA in a bacterial clone library. To distribute the library, the bacterial clones were first cultured and aliquoted in a 96-well microplate format by the commercial vendor. The original template plates are often duplicated in each laboratory and used to set up reactions by either a robotic liquid-handling system (in our laboratory) or manually with a multichannel pipettor. The PCR products are then purified for final array printing.

It is obvious that any high-throughput operations that involve multiple steps of sample handling and processing, such as microarray production, can be subject to error. For example, the clones were sequence verified upon addition to the Consortium, but the collection that was duplicated and sent to Research Genetics for distribution had a $12 \%$ well error rate (http://image.llnl. gov/image/qc/bin/display_error_rates).

Furthermore, there are many steps between library duplication and microarray printing where errors could be introduced. Any one of a number of problems, from incorrect database information provided by the company to PCR contamination or mistakes made in the manual handling of the clones, could lead to misidentification of genes. In this report, we demonstrate that a sequence verification step late in the production process is required to identify and correct for such errors.

\section{MATERIALS AND METHODS}

\section{Clone Preparation}

A sequence-verified cDNA clone library was purchased from Research Genetics. Clones from 32-gene-dense plates in 96-well format were transferred from the frozen bacterial stock to culture plates by scraping the wells with barrier tips on a multichannel pipettor, then swirling the tips in the corresponding wells of LB media. The clones were grown at $37^{\circ} \mathrm{C}$ for $1-2$ days. A robotic sample processor (Genesis; Tecan, Raleigh, NC, USA) was used to set up reactions with $5 \mu \mathrm{L}$ bacterial culture in $100 \mu \mathrm{L}$ total volume. After thermocycling, the robot was again used for PCR purification with PCR purification plates (Millipore, Bedford, MA, USA). The purified clones were manually transferred to storage plates using a multichannel pipettor. The PCR products were run on
Table 1. Gel Analysis of All Clones before Assembling into Final Plate Format

\begin{tabular}{|lrr|}
\hline $\begin{array}{l}\text { Gel } \\
\text { Analysis }\end{array}$ & $\begin{array}{c}\text { No. of } \\
\text { Clones }\end{array}$ & $\%$ \\
\hline Correct size & 1918 & 63 \\
Incorrect size & 211 & 7 \\
Multiple bands & 408 & 13 \\
Low or no yield & 534 & 17 \\
$\begin{array}{l}\text { Total clones } \\
\text { amplified (32 plates) }\end{array}$ & 3072 & 100 \\
\hline
\end{tabular}

Table 2. Quality-Control Sequencing Results

\begin{tabular}{|c|c|c|}
\hline & $\begin{array}{l}\text { No. of } \\
\text { Clones }\end{array}$ & $\%$ \\
\hline \multicolumn{3}{|c|}{ Correct Size (107) } \\
\hline $\begin{array}{l}\text { Correct } \\
\text { sequence }\end{array}$ & 91 & 85 \\
\hline $\begin{array}{l}\text { Incorrect } \\
\text { sequence }\end{array}$ & 16 & 15 \\
\hline \multicolumn{3}{|c|}{ Incorrect Size (121) } \\
\hline $\begin{array}{l}\text { Correct } \\
\text { sequence }\end{array}$ & 97 & 22 \\
\hline $\begin{array}{l}\text { Incorrect } \\
\text { sequence }\end{array}$ & 24 & 78 \\
\hline
\end{tabular}

$1 \%$ agarose gels to check for purity and to verify size. Products that showed multiple bands were gel purified and replaced into the original wells. Products with low or no yield were omitted. Most of the products showing incorrect size were omitted. Twenty-four master plates were manually assembled from the remaining clones.

\section{Sequencing}

The master plates of cDNA clones were then cycle sequenced with fluorescent dye-labeled terminators using an ABI PRISM ${ }^{\circledR}$ BigDye $^{\circledR}$ Terminator Cycle Sequencing kit with AmpliTaq ${ }^{\circledR}$ DNA polymerase, FS (both from Applied Biosystems, Foster City, CA, USA), $1 \mu \mathrm{L}$ PCR template, and 3.2 pmol primer in a final volume of $20 \mu \mathrm{L}$. Thermal cycling was conducted on a DNA Engine Tetrad ${ }^{\mathrm{TM}}$ Thermal Cycler (MJ Research, Waltham, MA, USA). Thermal cycling conditions were $96^{\circ} \mathrm{C}$ 
Table 3. Results of Data Analysis by Rocket

\begin{tabular}{|lcc|}
\hline $\begin{array}{l}\text { Rocket } \\
\text { Analysis } \\
\text { Results }\end{array}$ & $\begin{array}{c}\text { No. of } \\
\text { Clones }\end{array}$ & $\%$ \\
\hline $\begin{array}{l}\text { Identified match } \\
\text { Identified } \\
\text { contaminant }\end{array}$ & 1824 & 79 \\
$\begin{array}{l}\text { Present in vendor } \\
\text { clone librarya }\end{array}$ & 279 & 20.5 \\
$\begin{array}{l}\text { Not present in vendor } \\
\text { clone librarya }\end{array}$ & 195 & $48^{\mathrm{a}}$ \\
$\begin{array}{l}\text { No Blast results } \\
\text { Total no. } \\
\text { clones analyzed } \\
\text { aproportion of identified contaminant. }\end{array}$ & $\frac{6}{2304}$ & 100 \\
\hline
\end{tabular}

for $10 \mathrm{~s}, 50^{\circ} \mathrm{C}$ for $5 \mathrm{~s}$, then $60^{\circ} \mathrm{C}$ for 4 min for a total of 25 cycles. The products were purified using MultiScreen ${ }^{\mathrm{TM}}$ 96-well plates (Millipore). The filtrates containing the purified sequencing products were then run on the $\mathrm{ABI}$ PRISM 3700 automated capillary sequencer (Applied Biosystems). Initial sequence analysis was performed using the Sequencing Analysis ${ }^{\mathrm{TM}}$ Software, version 3.6 (Applied Biosystems).

\section{Sequence Analysis}

The nucleotide sequence data from each reaction was individually copied from the model 3700 Sequence Analysis software into a text file without discerning the quality of the sequence results except to determine if the run was successful. The files were then converted to FASTA format, where each de- scription line identified the clone location provided by Research Genetics.

Analysis of the sequence data was performed using an in-house sequence verification program called Rocket. The default assumption built into the program was that the information supplied by the vendor was correct. The algorithm was structured to verify correctness quickly, reverting to more complicated searches only if the initial tests failed.

The first test the program performed was a BLAST2 search (10) of the sequence from our text file against the GenBank ${ }^{\circledR}$ accession number (2) provided by the vendor using a BLOSUM62 clustered scoring matrix and the default parameter settings at the National Center for Biotechnology Information Web site (http://www. ncbi.nlm.nih.gov/blast/bl2seq/bl2.htm). This choice of parameters did not require exact matches; thus, it overlooked minor errors in sequencing. If the BLAST2 search matched successfully, then the result was written to a log file and the program moved on to consider another clone.

If the BLAST2 search failed to find a match, then the program used our sequence to perform a full BLAST search (1) against the non-redundant human database (7) to find the ten best matches. The algorithm found the current UniGene cluster numbers (8) for both the clone information provided by the vendor and for each of the top 10 matches to the sequence. If any of the UniGene cluster numbers agreed, then the result was logged as a match between the sequence and the accession number.

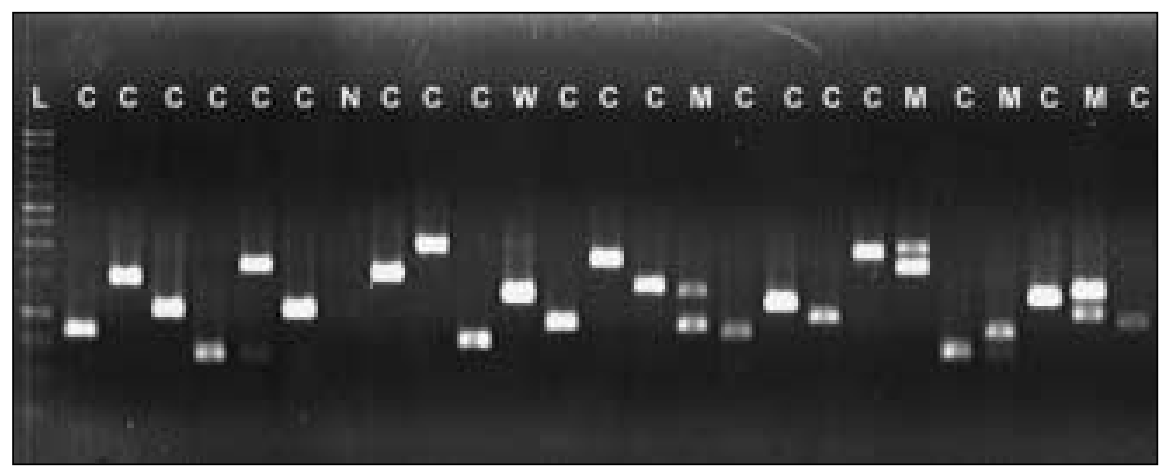

Figure 1. Agarose gel of purified PCR-amplified clones. The PCR products of the cDNA clones were run on a $1 \%$ agarose/TAE gel, then stained with ethidium bromide. Each product was evaluated for quality and size of the band. L, ladder, M, multiple bands, C, pure bands of correct size, N, no or low product, $\mathrm{W}$, wrong or incorrect size band. 


\section{Short Technical Reports}

If the combined BLAST/UniGene procedure failed to match the accession number, then an error was logged and the algorithm searched for contamination from other clones supplied by the vendor. This was accomplished by searching with the top 10 UniGene cluster matches for our sequence against other UniGene clusters in the information supplied by the vendor. If a match was found in this way, then a confirmation of the result was attempted by using another BLAST2 search of our sequence against the matching accession number. If this succeeded, then it was logged as a match to a contaminating clone.

Finally, if all attempts at identifying the sequence inside the data failed, then an error was logged and the accession number of the best match from the full BLAST search was used to annotate the clone.

\section{RESULTS AND DISCUSSION}

The PCR products amplified from cDNA clones were first analyzed on a $1 \%$ agarose gel. Each lane corresponds to one clone. Most lanes (70\%) showed a single strong band, whereas some lanes showed multiple bands or had low yield or no amplification (Figure 1). Each single-banded product was compared to the database for clone insert size (Table 1). Most showed correct size $(63 \%)$, and some showed incorrect size $(7 \%)$. Checking the size of the PCR products against the database helped detect potential gross errors, such as plate inversions. On many occasions, the lanes containing more than one band had a band of correct size and a band corresponding to the size of a neighboring well, suggesting a potential cross contamination. Several original bacterial stocks that showed multiple bands after PCR were streaked onto new LB plates, and a number of individual colonies were picked and PCR amplified. Gel electrophoresis indicated that two populations of cells often existed, suggesting that cross contamination may have occurred during library duplication. Because restoration of the correct clone by this approach was time consuming, we opted to gel purify the band with the correct size.

To evaluate whether DNA size is a reliable indicator for the clones, we picked a similar number of clones with correct size (107) and incorrect size (121) for sequencing. After sequencing, they were searched by BLAST. As shown in Table 2, even among the correct size group, $15 \%$ did not match the genes named in the database. Interestingly, among the incorrect size group, $22 \%$ actually matched the genes named in the vendor's database. This observa-

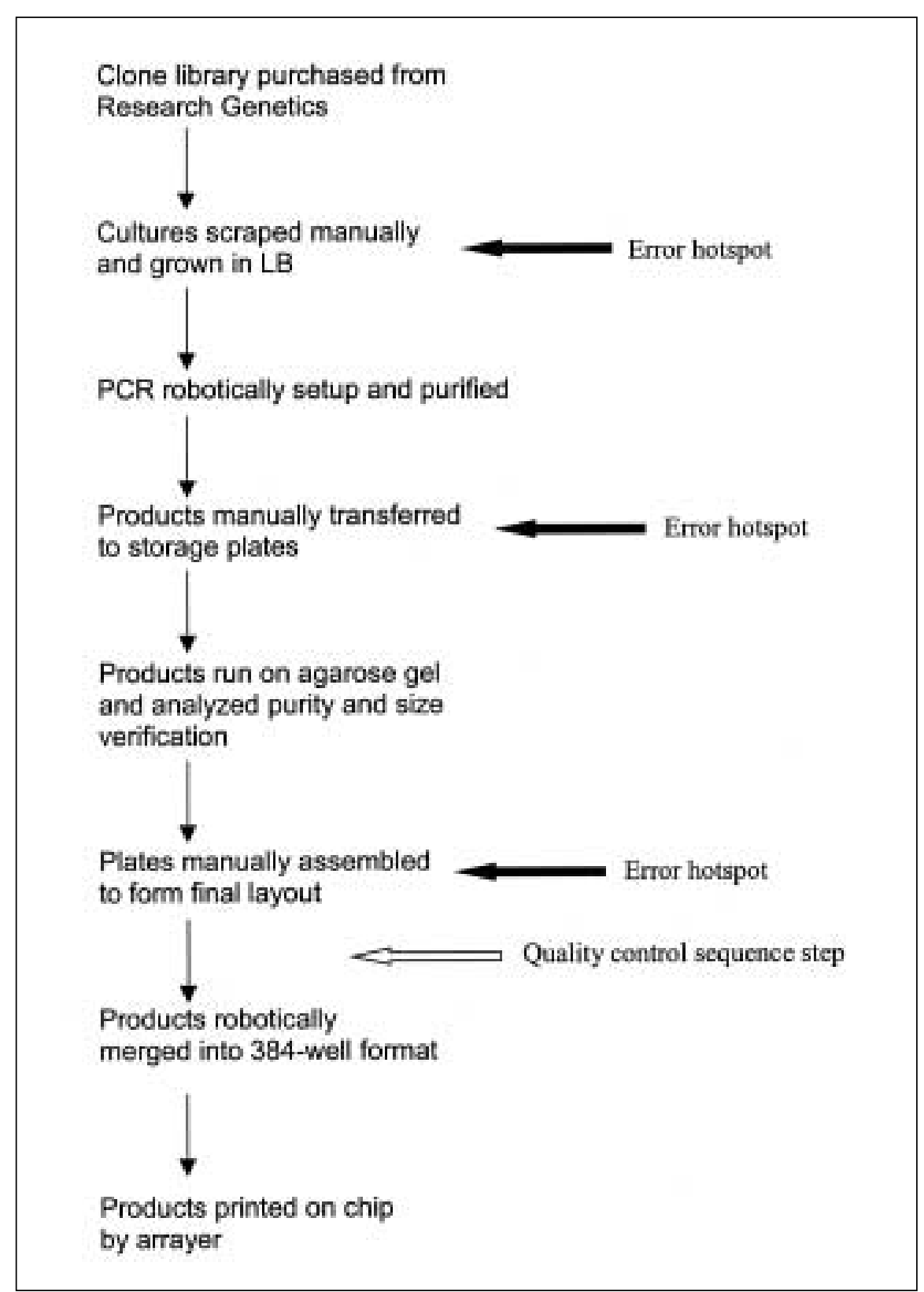

Figure 2. Flowchart summarizing clone preparation procedure. Black blocked arrows indicate steps where hot spots for errors are most likely to occur. These steps were performed manually with a multichannel pipet or a single-channel pipet. The white arrow indicates the quality-control sequencing step, after all clone amplification and handling were complete. tion led us to two conclusions. First, there can be errors in clone size entry in the vendor's database. Second, to guarantee that the names match the clones on our array, a final sequencing step is needed.

After sequencing was performed on the 24 assembled master plates containing the final cDNA for microarray printing, the sequences were matched against GenBank using the Rocket pro- 
gram (see Materials and Methods). Only $79 \%$ of the clones matched the expected genes given in the database (Table 3). The other $21 \%$ either matched a contaminant from another clone or did not match anything in the database. Six clone templates were not clean enough to get quality sequence results. Because the clone library was created with a $12 \%$ well error rate and gel electrophoresis did not positively detect clone identities, it is not surprising that a $21 \%$ error rate was found after handling and processing the clones.

Figure 2 summarizes the steps involved in producing microarray chips. Each step that included the manual transfer of clones (usually with a multichannel pipet) could have introduced unknown errors. For instance, when the frozen cultures were stabbed with a 12channel pipettor and then swirled in the corresponding row of LB media, care was taken to line up the row from the original culture plate with the same row in the LB plate. Any inversions could go unnoticed until the quality-control sequencing step. Also, during the plate assembly step, many partial plates were converged by hand into one master plate. Database tracking was a particular challenge for these individual clones. In Figure 2, the quality-control sequencing step is highlighted with a white arrow. This step was performed after the master plates were assembled and before each master plate was robotically merged into 384-well plates and printed on the microscope slides.

Thus, several steps between the production of the clone library and printing on the chips could account for the $21 \%$ error rate. Database tracking for bacterial growth, PCR amplification and purification, and robotic merging into 384-well plate format does not recognize pipetting errors, contamination, or incorrect data received from the vendor. This issue has not been adequately addressed in the literature. Our analysis suggests that for good quality control, it is essential that these mistakes are identified and accounted for during the final stages of microarray production.

\section{REFERENCES}

1.Altschul, S.F., W. Gish, W. Miller, E.W. Myers, and D.J. Lipman. 1990. Basic local alignment search tool. J. Mol. Biol. 215:403410

2.Benson, D.A., I. Karsch-Mizrachi, D.J. Lipman, J. Ostell, B.A. Rapp, and D.L. Wheeler. 2000. GenBank. Nucleic Acids Res. 28:1518.

3.Bittner, M., P. Meltzer, Y. Chen, Y. Jian, E. Seftor, M. Hendix, M. Radmacher, R. Simon et al. 2000. Molecular classification of cutaneous malignant melanoma by gene expression profiling. Nature 406:536-540.

4.Clark, E.A., T.R. Golub, E.S. Lander, and R.O. Hynes. 2000. Genomic analysis of metastasis reveals an essential role for RhoC. Nature 406:532-535.

5.Fuller, G.N., C.H. Rhee, K.R. Hess, L.S. Caskey, R. Wang, J.M. Bruner, W.K.A. Yung, and W. Zhang. 1999. Reactivation of insulin-like growth factor binding protein 2 expression in glioblastoma multiforme: a revelation by parallel gene expression profiling. Cancer Res. 59:4228-4232.

6.Lennon, G.G., C. Auffray, M. Polymeropoulos, and M.B. Soares. 1996. The I.M.A.G.E. Consortium: an integrated molecular analysis of genomes and their expression. Genomics 33:151-152.

7.Madden, T.L., R.L. Tatusov, and J. Zhang. 1996. Applications of network BLAST server. Methods Enzymol. 266:131-141.

8.Schuler, G.D. 1997. Pieces of the puzzle: expressed sequence tags and the catalog of human genes. J. Mol. Med. 75:694-698.

9.Southern, E., K. Mir, and M. Shchepinov. 1999. Molecular interactions on microarray. Nat. Genet. 21:5-9.

10.Tatusova, T.A. and M.L. Thomas. 1999 Blast 2 sequences - a new tool for comparing protein and nucleotide sequences. FEMS Microbiol. Lett. 174:247-250.

This work was partially supported by a donation from the Michael and Betty Kadoorie Foundation, the Tobacco Settlement Funds as appropriated by the Texas State Legislature, and grant no. 0036570039-1999 from the Texas Higher Education Coordination Board to W.Z. Address correspondence to Dr. Wei Zhang, Director, Cancer Genomics Laboratory, Department of Pathology, University of Texas M.D. Anderson Cancer Center, Houston, TX 77030, USA.e-mail:wzhang@mdanderson.org

Received 19 December 2000; accepted 16 March 2001.

E. Taylor, D. Cogdell, K. Coombes, L. Hu, L. Ramdas, A. Tabor, S. Hamilton, and W. Zhang The University of Texas M.D. Anderson Cancer Center Houston, TX, USA 